\title{
Ensino e pesquisa em Comunicação: da teoria versus prática à composição contexto \& profissão'
}

José Luiz Braga

Professor titular no PPG em Ciências da Comunicação Universidade do Vale do Rio dos Sinos (Unisinos).

E-mail: jlbraga@via-rs.net

O tema traz inevitavelmente à cena a conhecida disjunção que marca a formação em Comunicação no País: a separação entre disciplinas teóricas e práticas. Essa disjunção, de certo modo, atravessa também as relações entre a graduação e a pós-graduação, produzindo uma descontinuidade marcante nos processos formadores entre os dois níveis. Compartilhamos os riscos dessa disjunção com outras áreas concomitantemente teóricas e praxiológicas como a Educação, o Direito, o Serviço Social - mas estas parecem dispor de encaminhamentos tradicionais para a questão, que ajudam a superar os riscos.

$\mathrm{Na}$ Comunicação Social, apesar do reconhecimento geral da disjunção, esta parece ser percebida, sobretudo, como a simples ausência de articulações entre dois componentes necessários. A formação teórica e a formação para os desempenhos práticos, enquanto componentes isolados, estariam bem elaboradas. Bastaria construir articulações entre um e outro componente, e a questão estaria superada.

Vejo, entretanto, a situação como um pouco mais grave - como um defeito estrutural que, para além das perdas decorrentes da ausência ou insuficiência de passagens entre os dois componentes, estigmatiza todo o processo formador. Essa constituição de uma cesura, em minha perspectiva, impede que qualquer dos lados se desenvolva além de certo limite, pois a própria distinção marcada constrói e atribui perfis, a cada âmbito, eivados de equívoco. A cesura é correlata a um pensamento que elabora teoria e prática como se estes dois modos pudessem se desenvolver isoladamente, passíveis de articulações posteriores, sobre materiais e processos prontos. Os dois modos seriam vistos como coisas independentes - a teoria como um modo de conhecimento, a prática como um

1. Texto apresentado em mesa-redonda no Intercom Sul - VII Simpósio da Pesquisa em Comunicação - Curitiba, maio de 2006. 
comunicação \& educação • Ano XII • Número 2 • maio/ago 2007

modo de fazer. Penso, diferentemente, que ambos são modos de conhecimento; e ambos são modos de fazer. E que dificilmente se possa conhecer - ou fazer - isoladamente, através de um só processo.

Se essa perspectiva é adequada, podemos afirmar que, não havendo interação desde os objetivos iniciais para a formação dos dois âmbitos, não há como construir articulações posteriores entre tais processos elaborados isoladamente.

\section{TEORIA \& PRÁTICA}

Para sustentar essa perspectiva, é preciso refletir sobre o que constitui a processualidade de cada um desses modos - teoria e prática - para enfrentamento dos desafios de conhecimento e de ação sobre as coisas, na área da Comunicação.

Devemos reconhecer que os processos de pensamento, descoberta, reflexão e trabalho intelectual não se esgotam na teoria pronta. Se o espaço da discussão teórica for inteiramente ocupado pelo ensino e pela aprendizagem do conhecimento estabelecido - teorias, no plural -, ainda que sejam escolhidos os melhores e mais relevantemente relacionados às necessidades do campo comunicacional, a aprendizagem desse material resulta estéril - ou, na melhor das hipóteses, dependente de competências eventuais e do talento ocasional dos estudantes para, no seu tempo externo ao curso de graduação, desenvolver relações com o mundo social, interacional, midiático e profissional.

Um dos limites dessa informação teórica é o risco de se apresentar descontextualizada e ausente de uma práxis que lhe possa dar sentido e atualidade (não no sentido de tempo presente, mas de competência atuante).

Correlatamente, os processos do fazer profissional, ligados às competências operatórias de produzir, criar materiais, desenvolver atividades inerentes a profissões do campo comunicacional, não se esgotam no adestramento das práticas canônicas. Mesmo que sejam desenvolvidas as atividades mais pertinentes, que os estudantes se tornem hábeis nos procedimentos mais reconhecidos como próprios e necessários das profissões que exercerão, esse fazer arrisca tornarse mecanicista e por isso desajustado das situações concretas que o estudante enfrentará na vida profissional - a menos que, por intuição ou talento próprio, se exercite nas transferências e adaptações do que aprendeu a circunstâncias às vezes muito diferenciadas. Não só pelas evidentes diferenças entre o laboratório, na Escola, e a oficina real, na empresa, mas também pelo deslocamento constante dos papéis profissionais e pelo surgimento de novos desafios do fazer, durante a vida profissional.

O âmbito da teoria exige contextualização, exige posições praxiológicas, exige fazeres e reflexividade. $\mathrm{O}$ âmbito das práticas impõe experimentação, enfrentamento de desafios, boas competências do aprender e reflexão.

Tenho a impressão de que, em nossos cursos, com excessiva freqüência, os dois lados, complementares mas adversários, acabam exercendo atuações muito parecidas, ainda que se pensem como opostas. Essas atuações, embora se vol- 
tem para objetos muito diferentes (o exercício da prática, de um lado; teorias e conceitos, do outro), arriscam se assemelhar em algumas dinâmicas. Uma delas é a passagem de informação pronta - isto é, assumida como evidente, não sujeita a reflexão, proposta sem exame de seus fundamentos, sem se perguntar a respeito de seus âmbitos de validade. Outra é a postura de bastar-se como modo de conhecimento, com tendência isolacionista.

\section{PESQUISA}

Nesse ambiente, a pesquisa se confunde com a teoria. $\mathrm{O}$ trabalho de pesquisar, pensado como atividade pura do pesquisador e como trabalho de âmbito abstrato, se desenvolveria no contato exclusivo com teorias.

Ora, teorias, enquanto conhecimento estabelecido, são apenas um instrumento de trabalho do pesquisador. O contato com a realidade - o mais próximo possível de como as coisas efetivamente são (reduzindo-se ao máximo os a priori) - é outra ação necessária da pesquisa. Além disso, é sempre objetivo da pesquisa produzir teoria. A expressão produzir deve ser assumida, aqui, no seu sentido mais literal, de atividade prática elaboradora e concreta - tanto quanto as ações reconhecidas de processo profissional: produções.

Mas não se deve confundir fazer teoria com fazer reflexões especulativas a partir de outras teorias. O processo de produção teórica é, sobretudo, um esforço de desentranhar da complexidade do mundo real elementos essenciais que nos ajudem a compreender e a descrever essa realidade. A teoria que majoritária e essencialmente se espera de nossos pesquisadores não é a grande teoria abstrata e generalizadora: é aquela próxima dos fenômenos, a teoria do concreto, mais imediatamente perceptiva de uma práxis comunicacional - a teoria da coisa vista, do processo percebido, a teoria do objeto.

É sobre essa teoria - na medida de sua acuidade sobre as coisas, de sua competência de perceber a possibilidade de apreensões modelizadoras do que se faz - que, por sua depuração sucessiva, por abstração crescente, poder-se-á criar, em contato com o pensamento mais avançado e elaborado, uma ampliação para percepções abrangentes que possam ser chamadas de grande teoria. E esta, por definição, é apenas uma parte culminante do processo - e por isso mesmo rara.

Ou seja: ninguém aprende a fazer teoria apenas pela visitação de grandes obras teóricas. É preciso ainda, e sobretudo, freqüentar realidades, tensioná-las pela reflexão e utilizá-las, por sua vez, para tensionar o estado atual do conhecimento estabelecido.

\section{CONSTRUÇÃO DA EXPERIÊNCIA}

O fazer profissional, mais do que ser pensado como uma prática já exercida (e que se deveria repetir com ou sem ajustes às circunstâncias), deve ser visto 
comunicação \& educação • Ano XII • Número 2 • maio/ago 2007

como um trabalho de enfrentamento de problemas práticos - os quais só com reflexão, ensaio-e-erro (experimentação escolada) e interação grupal produtiva temos condições de levar a bom termo.

O melhor profissional de Comunicação não é aquele que dispõe de melhores informações prontas sobre o que fazer, mas quem transfere suas informações para situações variadas, muito específicas, sendo capaz de apreender, a partir do próprio problema de ação a enfrentar, seus desafios específicos.

Isso significa que a ação realizada não leva apenas a um trabalho bemfeito; permite também ampliar o repertório gerando experiência. A construção da experiência depende de outras coisas além da repetição adestradora de gestos até que nos tornemos habituados a fazê-los sem hesitação. Envolve ainda articulações compreensivas entre o problema enfrentado e seus contextos; entre o problema e as soluções obtidas; e entre problemas diferentes, com suas complementaridades e tensionamentos. Devem-se incluir, ainda, articulações compreensivas entre as questões concretas enfrentadas e as teorias que falam de tais questões, para perceber o que cada um desses dois componentes do conhecimento oferece e o que deixa a dever com relação ao outro.

Em síntese, a construção da experiência depende de reflexão, de tentativas e de interação grupal produtiva, na medida em que se possam tirar conseqüências, em aprendizagem pessoal, de tais processos. Isso deve valer para os profissionais e, por isso mesmo, para os processos interativos entre estudantes e entre professores.

\section{COMPOSIÇÃO CONTEXTO \& PROFISSÃO}

Se tais reflexões fazem sentido, deveríamos superar aquele processo informacional (sempre relevante, mas insuficiente) que caracterizamos anteriormente como um mesmo tipo de gesto (passar informações) sobre dois objetos diferentes - um deles, teorias, o outro, práticas.

Seria preciso pensar o currículo de graduação como uma oportunidade para realizar, articuladamente, diversos fazeres sobre um mesmo tipo de objeto. Nesse ângulo, o objeto complexo que exigiria aquela variedade de atividades seria o processo da midiatização efetivamente existente enquanto fenômeno social - envolvendo as práticas profissionais, a recepção que é prevista e a que é dada aos produtos dessas práticas, e os processos críticos e de interação social, segundo os quais tais produtos circulam entre as pessoas e retornam ou não ao âmbito da produção². O objeto inclui também - é claro - as condições de produção e as condições de reconhecimento, na sociedade, do que se produz

2. Sobre os processos de interação social, nesta perspectiva, ver BRAGA José Luiz. A sociedade enfrenta sua mídia: dispositivos sociais de crítica midiática. São Paulo: Paulus, 2006. e que circula; os contextos sociais, políticos e culturais em que cada tipo de produção se desenvolve e passa a ser trabalhado pela sociedade.

A variedade de fazeres é certamente muito maior do que uma separação simplificadora entre pensar abstratamente e fazer tecnicamente. Toda disciplina de um curso que possa ser facilmente colocada em uma ou outra, apenas, dessas 
duas áreas supostamente separadas de atuação, provavelmente é tão simplista quanto a cesura recorrente. Ao contrário, com dosagens muito variadas de concretude e abstração, a cada caso, parece ser possível pensar em fazeres sobre componentes específicos daquele objeto complexo (que é o objeto dos estudos e das práticas da Comunicação): práticas; reflexões; experiências (no sentido de ensaio-e-erro - o que envolve, por sua vez, reflexividade crítica); testagem de proposições abstratas através de ações práticas; falar sobre processos concretos nos termos desta ou daquela teoria; exercício do aprender a aprender como componente relevante da formação de experiência (o que reuniria ações concretas, reflexões abstratas, aportes do conhecimento prático estabelecido e aportes do conhecimento teórico estabelecido); trabalho analítico-crítico sobre produtos prontos e circulando na mídia, e certamente muitos outros fazeres.

Esse conjunto de ações não pode ser distribuído separadamente - a cada disciplina, um tipo de ação. A experiência concreta de uma disciplina certamente envolve vários fazeres, com ênfases diversas. Para o conjunto de disciplinas que compõem um curso de graduação, uma outra composição deveria ser feita: entre práticas-e-teorias de uma formação especializada, de um lado; e, de outro, a percepção, a compreensão, a descrição, assim como reflexões sobre os contextos gerais da sociedade em que aquela especialidade se desenvolve. Tais contextos envolvem, naturalmente, um conhecimento básico de sociedade - em ângulos sociológicos, históricos, culturais e antropológicos pertinentes a uma sociedade midiatizada. O que significa que não se trata de fazer sociologia, política, etnografia, mas sim que os estudantes desenvolvam (eventualmente usando recursos da própria circulação midiática) uma percepção suficientemente complexa sobre essa sociedade, em que sua futura profissão será exercida. Como a sociedade é a mesma para todas as profissões de Comunicação, e, sobretudo, como determinadas características da sociedade midiatizada atravessam e solicitam todas as especialidades, é nesse terreno principal que as diferentes profissões do campo se encontram, enquanto profissões de Comunicação. Por isso mesmo, essa clivagem principal proposta não arriscaria demarcar-se como cesura, como fronteira de desconhecimento mútuo (o que parece acontecer na atual clivagem), mas sim como âmbito organizador no qual se articulam estudos do contexto e estudos de uma especialidade profissional.

Nossa proposta decorre de tais reflexões. Não é o ângulo teórico que deve se caracterizar como parte comum na formação profissional (enquanto o ângulo prático-profissional se definiria como parte especializada). Diversamente, a parte comum deve se caracterizar como estudos de contexto - no qual se encontram informações e teorias de sociedade, assim como teorias e práticas das demais profissões da área, reunidas pelo ângulo de processos midiáticos. Estes processos podem ser descritos a partir de um conjunto de disciplinas, e podem ser trabalhados praticamente, enquanto âmbito de intervenção e compreensão de fenômenos da realidade social. Tais estudos envolveriam tanto a observação do mundo empírico, com suas práticas, como as teorias gerais descritivas e compreensivas do campo. 
comunicação \& educação • Ano XII • Número 2 • maio/ago 2007

A parte especializada, voltada para as profissões de jornalista, publicitário, audiovisuais, relações públicas etc. (incluindo-se aí as possibilidades de interfaces e especialidades renovadas), não se esgota no exercício de práticas, devendo incluir-se igualmente fazeres concretos e fazeres de reflexão, a busca de informação e de experiência, assim como processos de percepção teórica.

Como é evidente, a distinção entre parte geral contexto e parte especializada profissões não determina disjunções, mas, ao contrário, composição.

\section{CONCLUSÃO}

Não tenho a menor dúvida de que existem muitas experiências produtivas que realizam, na prática, processos integradores e articulados, do tipo que aqui proponho. Em cada universidade e em cada curso de graduação em Comunicação, sabemos de professores dedicados e criativos que estão tentando ultrapassar aquela cesura simplificadora. É dessa prática que surgirão novas perspectivas para a formação na área. Tenho a expectativa de que as presentes reflexões tenham sintonia com suas experiências. Gostaria de enfatizar que, para a realização ampla da superação pretendida, será preciso, além das experiências pontuais, relacionadas a disciplinas ou conjuntos de disciplinas, rever o próprio conceito da organização curricular, gerando outros modos para situar e sistematizar cada disciplina de modo articulado no conjunto geral da formação.

Nesse espaço, em que uma outra clivagem, distinta da teoria versus prática, seja construída - na nossa perspectiva, através de uma articulação entre contexto social e especialidade (ambos com suas práticas e suas reflexões abstratas) -, qual seria o papel da pesquisa?

A pesquisa, por definição, envolve a ida à realidade empírica, a busca de fundamentos teóricos, o objetivo de ampliação do conhecimento e a compreensão dos fenômenos, na sua existência social; e o propósito de contribuir para descobertas, para novas formalizações e para o bom desempenho da práxis. Estas tarefas podem ser realizadas no âmbito das atividades especializadas, na esfera do conhecimento do contexto social e, ainda, como conceito geral de aprendizagem.

Assinalamos, antes, a capacidade de aprender a aprender como um componente relevante na formação da experiência - e sabemos que a experiência é um elemento central no exercício de uma profissão.

Em livro sobre Comunicação e Educação, Regina Calazans e eu, no capítulo intitulado "Autoformação"', fizemos um levantamento de competências que caracterizariam a pessoa capaz de organizar sua própria aprendizagem. Constatamos, após elaborarmos esta listagem, que ela corresponde muito de perto às competências solicitadas para a atividade prática fazer pesquisa. Esta aparece, então,

3. BRAGA, José Luiz; CALAZANS, Regina. Comunicação e Educação: questões delicadas na interface. São Paulo: Hacker, 2001 como o desenvolvimento de competências para a reflexão estruturante enquanto dimensão fundamental da auto-aprendizagem (sobre as coisas do mundo).

Aprender a pesquisar, em uma graduação de Comunicação, não corresponde simplesmente a formar-se para uma vida acadêmica de pesquisador (que, mesmo 
aí, deveria ser recusada como atividade puramente abstrata). Na graduação, aprender a fazer pesquisa é também - e, talvez, principalmente - um exercício prático em que se pode aprender a organizar sua própria aprendizagem como competência fortemente requerida em todas as profissões, mormente aquelas do campo da Comunicação.

A pesquisa seria, então, o principal articulador do que estou chamando de parte comum e de parte especializada. Poderíamos ver a pesquisa como um fator articulador entre a vida profissional e a busca de conhecimentos, entre a graduação e a pós-graduação, entre os estudos e as profissões. Até porque nenhum exercício profissional se faz, com competência, se não for capaz de desenvolver tais articulações. Sabemos que bons profissionais o fazem. Apenas seria relevante que, em vez de dependerem de puro talento e de esforço pessoal, na história de suas experiências profissionais, já chegassem ao campo de trabalho razoavelmente preparados para construir relações entre coisas e conceitos.

E, fazendo-o, aprender com sua própria experiência.

Resumo: $\mathrm{O}$ artigo aborda criticamente a situação do ensino e da pesquisa nos cursos de graduação em Comunicação do País. Analisa a conhecida disjunção entre teoria e práticas, nessa formação, relacionando-a a uma perspectiva equivocada sobre os dois âmbitos, mais do que a uma simples ausência de articulações no currículo. Desenvolve algumas perspectivas sobre as atividades de fazer teoria e de fazer profissional para assinalar sua interdependência. Apresenta, então, a proposta de substituir a contraposição teorias versus práticas, na organização das formações em Comunicação, por uma composição não-disjuntiva entre contextos (sociais e de processos midiáticos) e formação profissional, envolvendo práticas e desenvolvimentos teóricos. A pesquisa é vista, aí, como processo prático-teórico e como práxis articuladora entre os dois âmbitos da formação.

Palavras-chave: ensino em Comunicação, formação profissional, pesquisa, currículo de graduação (Comunicação).
Abstract: This article is a critical approach to the situation of teaching and research in the Undergraduate Courses of Communication in Brazil. It analyzes the well-known disjunction between theory and practice in this course, relating it to a mistaken perspective about the two domains rather than attributing this disjunction to a simple absence of articulation in the curriculum. It develops some perspectives about the activities of making theory and doing it professionally, in order to point out their interdependence. It then presents a proposal for substituting the opposition between theories and practices in the making of curricula for Communication courses, for a non-disjunctive composition between (social and media process-related) contexts and professional courses, involving both practice and theoretical development. Research is then seen as a practical and theoretical process and as an articulating practice between the two course domains.

Keywords: teaching in Communication, professional courses, research, undergraduate course curriculum (Communication) 